\title{
Inovação, rigor e ascese entre a vida e a obra de Vinicius Caldeira Brant
}

\author{
FRANCISCO DE OLIVEIRA
}

RESUMO: Vinicius Caldeira Brant não deixou uma obra extensa, mas sua produção pode ser considerada exemplar na literatura sociológica brasileira. Seu artigo clássico sobre o desenvolvimento capitalista na agricultura, estudando o caso concreto da região de Assis, em São Paulo, certamente mudou a direção dos estudos e pesquisas sobre a agricultura no Brasil, indicando que era o novo desenvolvimento capitalista que estava gerando os novos problemas e não apenas o velho latifúndio. Dedicando-se, posteriormente, ao estudo do sistema carcerário paulista - que, por extensão, pode ser paradigmático do caso brasileiro- confirmou o que hoje é sabido, isto é, a desmitificação dos mitos sobre o prisioneiro típico, branco, paulista e alfabetizado, ao contrário dos estereótipos, ao mesmo tempo que demonstrou a vil exploração de quem já é cerceado de sua liberdade, por algumas empresas. A economia interna dos presídios é formada por um misto de superexploração, tráfico de drogas, formação de perversos códigos de sociabilidade, sob as vistas complacentes do Estado. Seu trabalho sobre Paulínia, petróleo e política, foi outra vez ao coração da matéria, mostrando a intrincada relação entre o caráter estatal da empresa e o sindicalismo petroleiro, co-fundador do novo movimento sindical brasileiro. Por último, mas não desimportante, utilizou metodologias inovadoras nesses estudos, nas quais o "objeto" deixa de ser passivo, para constituirse em co-autor das escolhas e perspectivas metodológicas. econômico também na produção acadêmica que publicou. Provavelmente ainda se encontrará nos seus pertences uma ou outra produção, que certamente não engordará de muito o número de seus títu-

PALAVRAS-CHAVE: desenvolvimento, agricultura, trabalho, prisão, sindicalismo, Vinicius Caldeira Brant.

Professor do Departamento de Sociologia da FFLCH - USP 
los que conhecemos; entre estes, provavelmente sua tese de doutorado em Paris, sob a orientação de Alain Touraine, seria de interesse para publicação.

Os que tiveram o privilégio de conhecê-lo recordam-no, em certa fase de sua vida, magro e alto, longos cabelos, entre o Quixote e Tiradentes, figuras que certamente eram de sua predileção. Didático na fala, abusando-se freqüentemente com a verborragia de discursos e falas acadêmicas. Longe, entretanto, de querer aparentar-se com os santos de alvaiade, nada do que era humano lhe foi estranho. Sua participação e contribuição rasgou todas as fronteiras ${ }^{1}$. Do mítico presidente da UNE no crítico período antes de 1964, que parlamentava com ministros e presidentes, - e algum ministro deve ter-lhe atribuído a perda do cargo - ao fundador de um partido revolucionário que, junto a outras formações políticas deram o combate à ditadura militar, ao exilado estudante de Paris, ao prisioneiro da ditadura, ao pesquisador do Cebrap, ao militante católico - surpreendente, para os que o sabiam conhecedor e seguidor de Marx -, ao professor da UFMG, ao fundador do Partido dos Trabalhadores, suas múltiplas atividades constituem uma cerrada unidade. Mas guardou sempre uma autocrítica tão rigorosa quanto a que exercitava em relação a terceiros, e sua risada sarcástica podia ser tão ácida quanto seus comentários certeiros e enxutos. Provavelmente riria também destes comentários.

Provavelmente seu trabalho mais conhecido é o de organizador da trilogia sobre São Paulo, que coordenou no Cebrap, patrocinada pela Comissão de Justiça e Paz da Arquidiocese de São Paulo, com D. Paulo Evaristo Arns. Foram publicados São Paulo, crescimento e pobreza, São Paulo, o povo em movimento e São Paulo, trabalhar e viver (cf. Brant, 1976; 1980; 1989). O primeiro da trilogia conheceu um êxito editorial quase sem precedentes no Brasil, mesmo para publicações patrocinadas pela Igreja Católica, cuja capacidade de divulgação e circulação faz inveja a qualquer editor. $\mathrm{O}$ impacto na opinião pública, mesmo sob a miserável censura da ditadura, foi tão grande que muitos atribuíram a bomba jogada nas instalações do Cebrap naquele ano a uma retaliação dos aparelhos mais sinistros da repressão militar-policial em São Paulo. É claro que para a ditadura isto não foi esquecido, e a fatura contra Vinicius acrescentou mais essa ao rol de suas atividades políticas anteriores.

O trabalho reunia uma série de artigos que, primeiro, reatualizou a equação, clássica para o marxismo, entre crescimento e pobreza, o país apenas saído do período do "milagre econômico", sob a férrula de Medici-Delfim Netto. Vale dizer, desmistificava, com as armas da ditadura, a suposta racionalidade técnica das políticas econômicas, servindo-se dos indicadores de uso

${ }^{1}$ Professor titular do Departamento de Sociologia da FFLCHUSP, aposentado. Diretor do Cenedic-Centro de Estudos dos Direitos da Cidadania, da mesma faculdade. corrente nas análises econômicas e sociais, o crescimento econômico: explicava a pobreza pelo crescimento! Isto era uma revolução teórica, sem nenhuma dúvida, mesmo para os que faziam oposição ao regime e que encontravam dificuldade para mostrar que o rei estava nu. A partir daí, passou a ser citação obrigatória em todos os títulos, não apenas para os panfletários de combate à ditadura ou os de denúncia do "modelo econômico", mas também para as 
análises da situação social, com base no desempenho da economia. E abriu, definitivamente, uma nova chave teórico-interpretativa para os estudos sobre a pobreza e, mais que isso, sobre a pobreza urbana. Hoje, aquele título talvez não impacte mais, devido à "banalização do mal", como diria Hannah Arendt, e, lido com a acumulação teórica gerada desde então, não pareça tão heterodoxo. Outras vozes mais autorizadas, sobretudo no seio da Igreja Católica, como a de D.Paulo Evaristo Arns, poderão ratificar quanto o trabalho de Vinicius e seus companheiros, naquele relatório que se transformou em livro, serviu às diretrizes pastorais que a Igreja Católica adotou sobre as questões da pobreza, do crescimento econômico e do urbano.

O segundo relatório, sempre sob o patrocínio da Comissão de Justiça e Paz, dava conta dos novos movimentos sociais, que cresceram como cogumelos na fecunda década dos 70, na cidade de São Paulo, como de resto em quase todo o país. Reunindo outra vez um conjunto de autores - muitos dos quais eram coautores, junto com Vinicius, do livro-bomba de cinco anos atrás - o trabalho ensaiava uma reflexão sobre como as condições do "crescimento e pobreza", apesar ou, às vezes, et pour cause, haviam dado lugar aos "novos" movimentos, às novas organizações populares, entre as quais, ações da Igreja Católica, nas comunidades de base, transformavam-se em verdadeiros viveiros de uma nova elaboração digamos, para usar um termo que ficou paradigmático a partir dali, da cidadania. Quer dizer, um povo "mole", "molenga", de origem rural e portanto sem consciência de classe, para uma sociologia pretensiosa e cegamente marxóide, retirava forças de sua própria precariedade, ensaiando novidades políticas que a República, em seus cem anos de existência, nunca havia conhecido. Ainda que o tema não fosse uma completa novidade para as ciências sociais que se renovavam, ele representou uma consolidação e uma aglutinação, com a cidade de São Paulo como eixo organizador, que revelava o novo país e as potencialidades da sociedade organizada para derrotar a ditadura chamando-a, no melhor estilo clausewitiziano, para um terreno, o das reivindicações e políticas sociais, insuperável pela pura repressão. Os movimentos sociais criaram, por assim dizer, uma nova política.

São Paulo, trabalhar e viver, o último da trilogia, de novo retornava ao tema de "crescimento e pobreza", abordando-o, desta vez, dos ângulos das condições de vida, de moradia, de saúde, de transporte, do emprego e do desemprego, este já surgindo como o flagelo - até então quase inédito para a cidade que vem liderando, por uma centena de anos, o desenvolvimento capitalista no país, - que veio para não mais recuar. Vinicius e seus colaboradores, alguns, poucos, que estiveram com ele na "seleção de ouro" dos tempos mais trevosos, sistematizaram um conjunto de informações, já bastante mais numerosas, disponíveis e confiáveis, que dava conta das precárias condições do povo trabalhador - pois é disso que se tratava - da segunda maior cidade da América Latina e mesmo do Novo Mundo.

A meu modo de ver, essa trilogia é a obra mais importante, em suas consequiências políticas, que saiu do grupo do Cebrap - e de alguns colaboradores de fora, convidados pelo Cebrap ou por Vinicius Caldeira Brant -, pro- 
duzida por aquela instituição. Não é a obra teoricamente mais ousada, embora não tenha sido irrelevante, nem seja hoje, em tempos do "pensamento único"irrelevante pôr em xeque uma concepção quase hegemônica que, a vários títulos, legitimou a ditadura, como hoje a estabilidade monetária legitima a coalizão conservadora no poder. Na produção de Vinicius - ele era o organizador da trilogia e compareceu sempre entre os autores - o lugar mais inovador e mais ousado, teoricamente, é de seu conhecido artigo Do colono ao bóia-fria: transformações na agricultura e constituição do mercado de trabalho na Alta Sorocabana de Assis (Brant, 1977). Na tradição dos estudos sobre a agricultura brasileira - e até, em certa medida, latino-americana - é a propriedade, e sua estruturação latifundista-minifundista, o ponto central, a pedra de toque para explicar não apenas a oposição "atrasado versus moderno" na própria agricultura, mas o subdesenvolvimento nacional e latino-americano: o chamado "modelo da Cepal" que redefiniu até uma certa tradição da interpretação feudal do campo brasileiro e latino-americano. Caldeira Brant deslocou essa centralidade, sem desconhecer a importância da extremada concentração da propriedade da terra, para a constituição do mercado de força de trabalho, e mais: era o desenvolvimento capitalista na agricultura que realizava esse deslocamento, e não a estagnação. Daí seu sugestivo e indicativo título “do colono ao bóia-fria”... Maria da Conceição D’Incao já havia publicado em 1975 seu clássico O bóia-fria, acumulação e miséria (D’Incao,1975) e Alberto Passos Guimarães, um dos autores mais representativos da tese do Brasil feudal, renovava-se com seu A crise agrária (Guimarães, 1979). Um novo ciclo, dando centralidade à industrialização da agricultura, enriquecia a bibliografia brasileira, fundamental para entender a nova riqueza e a nova pobreza, a União Democrática Ruralista, a celerada UDR, e os deserdados do campo, cujo emblema maior é o Movimento dos Sem-Terra. A matriz teórica de Vinicíus era, certamente, o próprio Marx, com sua tese da industrialização e simultânea desfeudalização do campo, e o Kautsky de A questão agrária (Kautsky,1968). Entre os brasileiros, Caio Prado Junior, que nunca militou nas teses do feudalismo agrário brasileiro, era a melhor inspiração.

O estudo de Vinicius interpretou corretamente as novas tendências em curso no Brasil, com a produção de bens de capital pela indústria nacional, com a oferta de caminhões, tratores, colheitadeiras, fertilizantes e defensivos, e a ação deliberada do capital bancário sobretudo através do Banco do Brasil. Assim, se a articulação especial da agricultura brasileira, no passado, que explicava o aparente feudalismo, havia sido o financiamento da industrialização pelos excedentes da agricultura "atrasada", no presente eram os excedentes de capital da indústria que financiavam a modernização da agricultura. Como ligação entre passado e presente, sob novas formas, o estatuto teórico-prático do trabalho, o "bóia-fria" de Maria da Conceição D'Incao, o "gato" intermediador e a manutenção de um pacto conservador entre a burguesia industrial, o velho latifúndio e o novo empresariado agrícola, de que Ronaldo Caiado, chefiando a UDR e armando novos jagunços, chegou a ser o mais lídimo representante. 
O tema da relação entre agricultura e força de trabalho não lhe era estranho. Pouco antes, em 1975, havia publicado pela então Estudos Cebrap (Brant, 1975), notas teóricas sobre o desenvolvimento da agricultura e a produção dos chamados excedentes populacionais, que é quase literalmente o título do artigo. Uma longa investigação sobre resultados de pesquisas demográficas na América Latina, realizada no Cebrap, serviu-lhe de andaime para essa reflexão. Deve-se notar que a demografia latino-americana, embora enfrente o desafio malthusiano, é presa no próprio círculo de giz da reflexão malthusiana. Vinicius rompeu com essa tradição indo de novo a Marx, e propondo a desmistificação do "círculo vicioso" de Malthus. Seus resultados não tiveram muita repercussão na trajetória da própria demografia brasileira e latino-americana que, embora milite contra as restrições à fecundidade e natalidade, não tem, propriamente, uma teoria da produção da população. Esta última quase sempre aparece como uma variável inteiramente independente, logrando-se, no máximo, correlações entre comportamentos sócioeconômicos e a dinâmica das populações.

Com sua equipe do Cebrap, Vinicius enveredou, no seu penúltimo trabalho naquela instituição, pelo campo do sindicalismo e da política. Desta vez, servindo-se de uma metodologia proposta por Alain Touraine, seu amigo e ex-orientador em Paris, a chamada "intervenção sociológica", Vinicius tomou a categoria dos petroleiros, notável - até a repressão de Fernando Henrique Cardoso à última grande greve dessa categoria - pelo seu poder de mobilização, que a havia tornado uma referência central para o novo movimento sindical brasileiro desde o final dos anos 70, projetandose também na política pela contribuição à formação do Partido dos Trabalhadores. Na "intervenção sociológica” os eternos objetos de pesquisa, que comparecem apenas, no melhor dos casos, nas entrevistas e trabalhos de campo, assumem, junto com os pesquisadores profissionais, a própria elaboração das investigações sobre si mesmos. Muda, portanto, a perspectiva: ao invés de serem olhados como "objetos", transformam-se em co-autores. A perspectiva teórica recebe, portanto, a influência direta das percepções, avaliações, expectativas e projetos pessoais e coletivos e políticos dos até então passivos pesquisados. Resultou um excelente livro - Paulínia, petróleo e política (Brant et alii, 1990), pois justamente o locus da pesquisa foi a refinaria do planalto paulista - que não encontrou muitos seguidores, pois a proposta teórico-prática de Touraine é francamente minoritária nas tradições tanto metodológicas quanto teóricas do campo das investigações da chamada sociologia do trabalho, aquela cujos objetos mais específicos são o mundo do trabalho e os movimentos sindicais. Mas esse trabalho de Vinicius e sua equipe deixou importantes sugestões, quando apenas se completavam dez anos da fundação do Partido dos Trabalhadores, justamente derivado da ação sindical e política de categorias entre as quais a dos petroleiros que, apesar de pequena numericamente, despontou com uma enorme centralidade nos movimentos dos anos 70/80. A questão do caráter estatal da Petrobrás, 
única empregadora dos petroleiros, surgia com toda centralidade, contribuindo para esclarecer muito do movimento do próprio sindicato.

O último trabalho de Vinicius Caldeira Brant na sua passagem pelo Cebrap foi a pesquisa sobre o trabalho nas prisões de São Paulo, centrado no Complexo do Carandiru, de que resultou o livro $O$ trabalho encarcerado (Brant, 1994). Uma pesquisa rigorosa, com questionários e entrevistas com presos, carcereiros e autoridades ligadas à administração prisional, realizada na Casa de Detenção e no presídio do Carandiru - do qual tinha experiência e conhecimento pessoal, pelos anos que passou lá como prisioneiro político da ditadura - em que o risco passava sempre por perto, levou-o intramuros, fazendo entrevistas inclusive com os presos mais temíveis e mesmo com aqueles ameaçados pelos duros códigos carcerários. As revelações dessa pesquisa podem ser resumidas em duas principais: a primeira diz respeito ao perfil dos encarcerados, desmentindo e desmistificando o estereótipo do negro, nordestino e analfabeto que encheriam o mundo da prisão. O trabalho de Vinicius e sua equipe, na qual se incluiu o saudoso Candido Procópio Ferreira de Camargo, fundador e pesquisador do Cebrap, revelou um perfil insuspeitado. Paulistas e não nordestinos, brancos e não negros, alfabetizados e não analfabetos, eram já, àquela época, a maioria dos prisioneiros do Estado. Hoje, pesquisa relatada pela Folha de $\mathrm{S}$. Paulo chega às mesmas conclusões, que são apresentadas como grande novidade. Embora os próprios códigos acertados pela equipe de pesquisadores com os presos não permitissem incursões teóricas-analíticas sobre os conflitos internos e a formação dos grupos e gangues naquele "complexo", ao leitor não ingênuo não seria surpresa mergulhar no inferno que veio a ser dramatizado pela narrativa de Dráuzio Varella no seu festejado livro Estação Carandiru (Varella, 2000).

A outra conclusão diz respeito, como o título indica, ao trabalho que os prisioneiros realizam, quer como terapia, para ajudar a passar o tempo, quer sobretudo como remuneração que os ajuda a manterem-se e às suas famílias. Esse trabalho não é irrelevante, de vários pontos de vista, e interessa muito a certas empresas que se beneficiam desse trabalho cujo grau de coerção é o mais alto entre todos: se o trabalho já é, por si, coerção, necessidade, imposição estranha ao trabalhador, na fórmula de Marx e Engels, o trabalho encarcerado ganha o campeonato. É um trabalho quase sem equivalência mercantil, pois as possibilidades de organização do trabalhador, para barganhar melhores salários e condições de trabalho, são quase nulas. Daí, duas conclusões são permitidas por essa corajosa abordagem das relações entre o mundo do crime e da penalidade e o mundo do trabalho: a primeira, a da reafirmação da coerção como característica do trabalho e a segunda, a da relevância do trabalho encarcerado para a economia. Nos EUA, cuja população encarcerada é a mais alta, proporcionalmente, do mundo capitalista, tanto o conjunto da população encarcerada não é irrelevante para o emprego e a taxa de desemprego norte-americanas, quanto sua contribuição ao PIB não pode ser desconsiderada. Os estudos a respeito não são tão 
OLIVEIRA, Francisco de. Inovação, rigor e ascese - entre a vida e a obra de Vinicius Caldeira Brant. Tempo Social; Rev. Sociol. USP, S. Paulo, 13(1): 1-8, maio de 2001.

comuns no Brasil, e o trabalho liderado por Vinicius Caldeira Brant não se arriscou a estimativas desse tipo, mas as sugestões e inferências qualitativas que ele proporcionou não são, por isso, menores.

A amizade que me ligou a Vinicius Caldeira Brant não me permite derramamentos que ele próprio renegaria. A sumária exposição de seus principais trabalhos não esgota o alcance de seus resultados. Sua vida foi demasiado rica para caber num curto artigo, que se quer de homenagem e de saudade. $\mathrm{O}$ Cavaleiro Andante andou, mas o ar do tempo brasileiro dele ficou impregnado.

Recebido para publicação em abril/2001

OLIVEIRA, Francisco de. Inovation, accuracy and asceticism in the life and work of Vinicius Caldeira Brant. Tempo Social; Rev. Sociol. USP, S. Paulo, 13(1): 1-8, May 2001.

ABSTRACT: Vinicius Caldeira Brant did not leave us an extensive production but, nevertheless, his work can be considered exemplary of Brazilian sociological literature. His classical article on capitalist development in agriculture, which is a case study of the Assis region, in the State of São Paulo, changed the direction of research and studies on agriculture in Brazil, showing that a major cause of the new problems was capitalist development and not only the old large landed estate. Later, studying the penal system in São Paulo which, can be considered paradigmatic of the whole Brazilian penal system, he confirmed what is current knowledge today, that is, he demystified the idea about the typical prisoner as being white, paulista and literate, contrary to the stereotype, at the same time as he exposed the prisoners exploitation by some business companies. The internal economy in the prisons is a mixture of overexploitation, drug dealing, the creation of perverse sociability codes under the eyes of the State. His work on Paulinea, oil and politics, again went straight to the heart of the matter, revealing an intricate relationship between the companies' public character and the oil workers union, co-founders of the Brazilian trade union movement. Last but not least, he used inovative methodologies in these studies, where the 'object' is no longer passive but becomes the co-author in the methodological choices and approaches.

\section{REFERÊNCIAS BIBLIOGRÁFICAS}

Brant, Vinicius Caldeira. (1975) Desenvolvimento agrícola e excedentes populacionais (Notas teóricas). Estudos Cebrap, São Paulo, (14): 101-118, outubro-novembro-dezembro. 
(org.). (1976) São Paulo 1975. Crescimento e pobreza. São Paulo, Edições Loyola.

. (1977) Do colono ao bóia-fria: transformações na agricultura e constituição do mercado de trabalho na Alta Sorocabana de Assis. Estudos Cebrap, São Paulo, (19): 37-91, janeiro-fevereiro-março.

. (1980) São Paulo, o povo em movimento. Petrópolis, Vozes.

. (1989) São Paulo, trabalhar e viver, São Paulo, Brasiliense.

. (1994) O trabalho encarcerado. Rio de Janeiro, Forense.

et alii. (1990) Paulínia, petróleo e política. Campinas/São Paulo, Sindicato dos Petroleiros de Paulínia e Campinas/Cebrap.

D’Incao, Maria da Conceição. (1975) O bóia-fria, acumulação e miséria. Petrópolis, Vozes.

Guimarães, Alberto Passos.(1979) A crise agrária. Rio de Janeiro, Paz e Terra.

KAUTSKy, Karl. (1968) A questão agrária. São Paulo, Flama.

Varella, Dráuzio. (2000) Estação Carandiru. São Paulo, Companhia Das Letras. 